\title{
Accuracy of Patients' Waiting Time Perceptions in the Emergency Department
}

Alina Abidova, $\mathrm{PhD}$ student ${ }^{1} \oplus$, Pedro Alcântara da Silva, $\mathrm{PhD}^{2}$, and Sérgio Moreira, $\mathrm{PhD}^{3}$

$I^{n}$ $\mathrm{n}$ a recent publication, Suriyawongpaisal et al. ${ }^{1}$ indicated that waiting time lies among the top priorities for patients. The researchers note that care providers should focus on managing perceptions rather than decreasing actual waiting time to improve patient experience. ${ }^{2}$ By means of actual waiting times, researchers can identify patients whose waiting time perceptions differ from the reality. Using recorded data from the hospital database, we demonstrate how patients' perceptions of waiting time diverge from the objective clinical data used as a reference point and identify the motives behind the formation of these inaccurate perceptions.

We obtained authorization to administer our study from the Ethics Committee and the Board of Directors and Administration of the Centro Hospitalar de Lisboa Ocidental E.P.E. (CHLO) and conducted our study in compliance with the ethical principles set out in the Declaration of Helsinki. Details of the sampling method used and the questionnaire are described in our previous study. ${ }^{3}$ Thus, we conducted a retrospective study of patients seen at an emergency department (ED) in the public hospital in Lisbon, Portugal, between January and December 2016. Data were collected between May and November 2017, resulting in a sample of 382 patients with a 5\% margin of error and a 95\% confidence interval. We asked each respondent to complete the survey questionnaire by mail or e-mail, according to individual preference, linking each response to the patient's clinical data for further analysis, namely, the waiting time for triage, the waiting time after triage, and the total time spent in the ED.

Our results show that patients of both sexes inaccurately perceive waiting times, with the majority overexaggerating their time spent waiting. We found that $19.7 \%$ of respondents accurately estimated the waiting time for triage, $21 \%$ the waiting time after triage, and $37.3 \%$ the total time spent in the ED, while $75.6 \%$ of patients overestimated the waiting time for triage, $68.7 \%$ the waiting time after triage, and $41.7 \%$ the total time spent in the ED. A total of $4.7 \%$ of respondents underestimated the waiting time for triage, $10.3 \%$ the waiting time after triage, and $21.1 \%$ the total time spent in the ED. Our results appear consistent with other studies in which the authors note that patients face apparent difficulty in correctly estimating the actual waiting time. ${ }^{4}$ A Tukey's HSD post hoc test revealed statistically significant differences regarding age group of patients $(\mathrm{F}(2,354)=4.80$, $\mathrm{p}=0.009)$ and prior frequency of $\mathrm{ED}$ experiences $(\mathrm{F}(2,239)=5.70, \quad \mathrm{p}=0.004)$. More specifically, our results showed that younger patients (mean $\pm \mathrm{SD}=49.42 \pm 20.16)$ and less frequent users of the $\mathrm{ED}$ (mean $\pm \mathrm{SD}=1.66 \pm 1.04$ ) more accurately estimated the total time spent in the ED. In turn, those who were older appeared more likely to overestimate (mean $\pm \mathrm{SD}=52.23 \pm 19.76)$ or underestimate this time (mean $\pm \mathrm{SD}=58.37 \pm 20.62$ ). Similarly, more frequent users of the ED appeared more likely to underestimate (mean $\pm \mathrm{SD}=2.31 \pm 2.19$ ) or overestimate the total time spent in the ED $($ mean $\pm \mathrm{SD}=2.75 \pm 2.94)$.

From the ${ }^{1}$ National School of Public Health, NOVA University of Lisbon; and the ${ }^{2}$ Institute of Social Sciences; and the ${ }^{3}$ Faculty of Psychology, University of Lisbon, Lisbon, Portugal.

Received February 16, 2020; revision received February 21, 2020; accepted February 22, 2020.

The authors have no relevant financial information or potential conflicts to disclose.

Supervising Editor: John $\mathrm{H}$. Burton, MD.

Address for correspondence and reprints: Alina Abidova, PhD student; e-mail: alinaabidova1@gmail.com.

ACADEMIC EMERGENCY MEDICINE 2020;00:1-2. 
Moreover, location (where patients spent the majority of their wait time) may impact the potential overestimation of the waiting time after triage, potentially influencing both quantitative (waiting time reported in hours and minutes) and qualitative (waiting time reported on a 1 to 10 evaluation scale, where 1 means "very long" and 10 means "very fast") perceptions of waiting time. Statistically significant differences were identified in all cases: quantitative perceptions $(\mathrm{F}(3,311)=42.53, \mathrm{p} \leq 0.01)$, qualitative perceptions $(\mathrm{F}(3,319)=20.43, \mathrm{p} \leq 0.01)$, and actual waiting time posttriage $(\mathrm{F}(3,325)=6.62, \mathrm{p} \leq 0.01)$. The results revealed that participants in a waiting room $(65.8 \%)$ perceived a longer waiting time after triage (mean $\pm \mathrm{SD}=4.66 \pm 1.40$ and mean $\pm \mathrm{SD}=$ $4.70 \pm 2.75)$ than those who spent the majority of their posttriage wait time on a stretcher in the observation room (mean $\pm \mathrm{SD}=3.54 \pm 1.80$ and mean $\pm \mathrm{SD}=5.38 \pm 3.20$ ) or in an observation room (mean $\pm \mathrm{SD}=3.10 \pm 1.45$ and mean $\pm \mathrm{SD}=$ $6.40 \pm 2.71$ ). Importantly, those participants in the observation room wait location waited longer on average after triage (mean $\pm \mathrm{SD}=2.56 \pm 1.52$ ) than those on a stretcher in the observation room (mean $\pm \mathrm{SD}=2.13 \pm 1.50$ ), which does not align with patients' perceptions. In turn, those who were treated immediately tended to underestimate waiting time posttriage (mean $\pm \mathrm{SD}=1.28 \pm 0.46$ vs. mean $\pm \mathrm{SD}=1.42 \pm 0.77$ )

Some patient groups were more likely to overestimate waiting time. First, we found that "standard," "urgent," and "very urgent" patients were more likely to overestimate the waiting time for triage (78\%), posttriage (70\%), and the total time spent in the ED (42\%). When comparing patients by the triage categories assigned by the staff, the results remained consistent with the above, with minor differences. Patients may differ from the staff that assign a triage category in their perceptions of urgency and the severity of the health condition. ${ }^{5}$ The researchers confirmed that patients overstate their priority level, on average, and disagree with the actual triage category given, with $48 \%$ of participants expecting to be assigned a higher priority versus only $20 \%$ expecting to be assigned a lower priority. ${ }^{5}$ Our test revealed statistically significant differences regarding the assigned triage categories $(F(1,261)=22.04, p \leq 0.01)$ and the duration of symptoms or complaints before coming to the $\mathrm{ED}(\mathrm{F}(1,287)=$ 4.51, $\mathrm{p} \leq 0.01$ ). More specifically, our results showed that participants who agreed with assigned triage category (75.5\%) perceived their situation to be a lower severity level (mean $\pm \mathrm{SD}=2.98 \pm 0.70$ ) than those who did not agree with assigned triage category (mean $\pm \mathrm{SD}=3.43 \pm 0.58$ ). Those participants who did not agree with assigned triage category (24.5\%) expected to be assigned a higher priority level and complained of symptoms for longer before going to the ED (mean $\pm \mathrm{SD}=4.63 \pm 1.79$ ) than those who agreed with their assigned triage category (mean $\pm \mathrm{SD}=$ $4.07 \pm 1.96)$.

Thus, assigned triage category may influence waiting time perceptions. In turn, the duration of symptoms or complaints before going to the ED may impact how patients perceive the assigned triage category and, in turn, influence the likelihood of agreement/disagreement with the assigned triage category.

\section{References}

1. Suriyawongpaisal P, Kamlungkuea T, Chiawchantanakit N, et al. Relevance of using length of stay as a key indicator to monitor emergency department performance: case study from a rural hospital in Thailand. Emerg Med Australas 2019;31:646-53.

2. Thompson DA, Yarnold PR, Williams DR, Adams SL. Effects of actual waiting time, perceived waiting time, information delivery, and expressive quality on patient satisfaction in the emergency department. Ann Emerg Med 1996;28:657-65.

3. Abidova A, Alcântara P, Moreira S. Predictors of patient satisfaction and the perceived quality of healthcare in an emergency department in Portugal. West J Emerg Med 2020;21:1-12.

4. Thompson DA, Yarnold PR, Adams SL, Spacone AB. How accurate are waiting time perceptions of patients in the emergency department? Ann Emerg Med 1996;28:652-6.

5. Toloo GS, Aitken P, Grilly J, FitzGerald G. Agreement between triage category and patient's perception of priority in emergency departments. Scand J Trauma Resusc Emerg Med 2016;24:126. 